\title{
Design of an observational strategy for quantifying the Southern Ocean uptake of $\mathrm{CO}_{2}$
}

\author{
Andrew Lenton, ${ }^{1,2,3}$ Richard J. Matear, ${ }^{4,5}$ and Bronte Tilbrook ${ }^{4,5}$ \\ Received 18 September 2005; revised 2 June 2006; accepted 30 June 2006; published 17 November 2006.
}

[1] A sampling strategy to estimate the annual mean $\mathrm{CO}_{2}$ uptake by the Southern Ocean was developed by applying two-dimensional Fourier transforms and signal-to-noise ratios to the simulated air-sea $\mathrm{CO}_{2}$ fluxes and $\triangle \mathrm{pCO}_{2}$ from an ocean biogeochemical model driven with NCEP-R1. Observations of $\mathrm{pCO}_{2}$ were used to validate the statistical properties of the model and to estimate the mesoscale variability not captured by the model resolution. Sampling regularly every 3 months, at every $30^{\circ}$ in longitude and $3^{\circ}$ in latitude is sufficient to determine the net Southern Ocean $\mathrm{CO}_{2}$ uptake. We applied this sampling strategy to the simulated air-sea fluxes to estimate a net annual mean $\mathrm{CO}_{2}$ uptake of $0.6 \pm 0.1 \mathrm{PgC} / \mathrm{yr}(1990-1999)$. This uncertainty in the estimate was dominated by the simulated interannual variability, and not by errors in the sampling or unresolved mesoscale variability. Therefore sampling at higher resolutions in space and time would not reduce the uncertainty in the Southern Ocean annual mean uptake any further. These results show that a doubling of the current Southern Ocean sampling (in longitude) would be required to constrain the net annual mean air-sea $\mathrm{CO}_{2}$ fluxes to within the natural variability of the system.

Citation: Lenton, A., R. J. Matear, and B. Tilbrook (2006), Design of an observational strategy for quantifying the Southern Ocean uptake of $\mathrm{CO}_{2}$, Global Biogeochem. Cycles, 20, GB4010, doi:10.1029/2005GB002620.

\section{Introduction}

[2] Atmospheric $\mathrm{CO}_{2}$ levels have continued to rise at unprecedented rates as a result of increases in anthropogenic activities such as fossil fuel burning, cement production and land clearing [Keeling and Whorf, 2003]. $\mathrm{CO}_{2}$ in the atmosphere acts as a potent greenhouse gas, and the increase in atmospheric $\mathrm{CO}_{2}$ is believed to be responsible for increases in global mean temperatures [Prentice et al., 2001]. Only about $40 \%$ of the $\mathrm{CO}_{2}$ emitted each year resides in the atmosphere. The remainder is taken up by the ocean and terrestrial biosphere. Current estimates suggest that $48 \%$ of the anthropogenic $\mathrm{CO}_{2}$ emitted (18001994) was taken up by the ocean [Sabine et al., 2004]. Oceanic uptake of $\mathrm{CO}_{2}$ slows the rate of atmospheric $\mathrm{CO}_{2}$ increase and thus illustrates the important role the ocean plays in slowing the rate of climate change.

\footnotetext{
${ }^{1}$ Institute for Antarctic and Southern Ocean Studies (IASOS), University of Tasmania, Hobart, Tasmania, Australia.

${ }^{2}$ Also at Antarctic Climate and Ecosystem Cooperative Research Centre (ACE CRC), University of Tasmania, Hobart, Tasmania, Australia.

${ }^{3}$ Now at Laboratoire d'Océanographie et du Climat: Expérimentations et Approaches Numériques (LOCEAN/IPSL), Université Pierre et Marie Curie, Paris, France.

${ }^{4}$ Antarctic Climate and Ecosystem Cooperative Research Centre (ACE CRC), University of Tasmania, Hobart, Tasmania, Australia.

${ }^{5}$ Also at CSIRO Marine and Atmospheric Research (CMAR), Hobart, Tasmania, Australia.

Copyright 2006 by the American Geophysical Union. 0886-6236/06/2005GB002620
}

[3] The primary pathway for atmospheric $\mathrm{CO}_{2}$ to enter the ocean is through gas exchange at the air-sea boundary. Air-sea $\mathrm{CO}_{2}$ flux is a function of the differences in partial pressures between the ocean and atmosphere across this boundary $\left(\Delta \mathrm{pCO}_{2}\right)$, and the gas exchange coefficient $(K)$, for example, following Wanninkhof [1992]:

$$
\begin{aligned}
C_{2} F L U X_{A I R-S E A} & =K\left(p C O_{2 A I R}-p C O_{2 S E A}\right) \\
& =K\left(\triangle p C O_{2 A I R-S E A}\right)
\end{aligned}
$$

[4] Air-sea $\mathrm{CO}_{2}$ fluxes are highly variable in space and time [Mahadevan et al., 2004; Volk and Hoffert, 1985] and balance to within $2 \%$ when integrated globally [Watson and Orr, 2003]. The 2\% difference corresponds to a net air-sea $\mathrm{CO}_{2}$ flux into the ocean of about $1.7 \pm 0.5 \mathrm{PgC} / \mathrm{yr}(1990-$ 1999) [Prentice et al., 2001].

[5] Estimates of Southern Ocean $\mathrm{CO}_{2}$ uptake obtained from model and observational studies ( 0.2 to $0.8 \mathrm{PgC} / \mathrm{yr}$ for the $1990 \mathrm{~s}$, south of $50^{\circ} \mathrm{S}$ ) show that the Southern Ocean is a net sink of $\mathrm{CO}_{2}$ but that the magnitude of this sink is poorly constrained [Matear and Hirst, 1999; Metzl et al., 1999; Rayner et al., 1999; Takahashi et al., 2002; Rödenbeck et al., 2003; Roy et al., 2003]. Most studies also suggest that the Southern Ocean is a region of high air-sea $\mathrm{CO}_{2}$ flux variability [Sabine and Key, 1998; Louanchi et al., 1999; McKinley et al., 2004] but with sparse data coverage (Figure 1). The lack of observations, particularly during the austral winter [Sweeney et al., 2002], is a function of sampling cost and the remoteness of the Southern Ocean. The combination of high variability and sparse data 


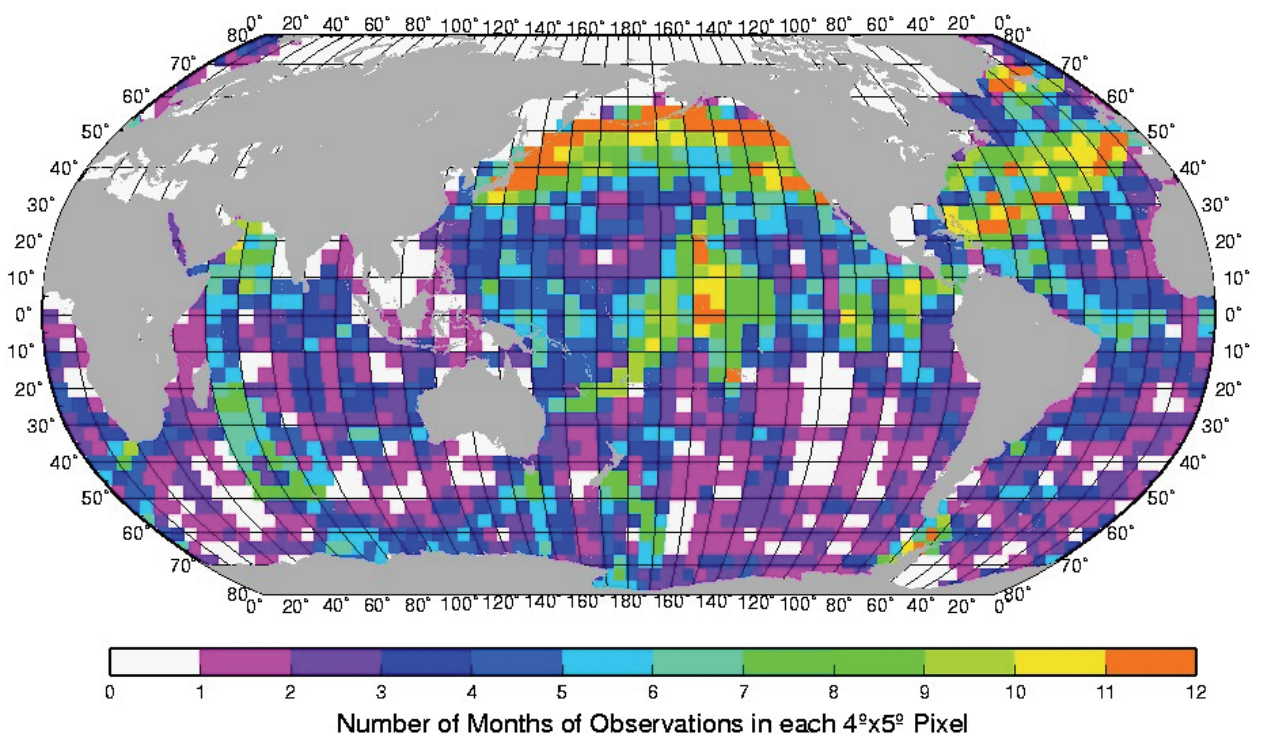

Figure 1. The number of different months during the year in which $\mathrm{pCO}_{2}$ data have been collected. A value of 0 refers to no data while a value of 12 signifies that observations have been collect in all months of the year. This map is a composite of more than 1.1 million observations made since 1958 [Sweeney et al., 2000].

coverage may explain the large range in estimates of Southern Ocean uptake.

[6] From an observational perspective, an important question is how the uncertainty in the Southern Ocean uptake may be reduced. Studies have attempted to quantify the sampling frequency required to accurately estimate air-sea $\mathrm{CO}_{2}$ fluxes. Garçon et al. [1992] in the North Pacific and Mémery et al. [2002] in the Mediterranean Sea both subsampled highly resolved observational time series of air-sea fluxes to estimate the temporal sampling required to constrain the annual net $\mathrm{CO}_{2}$ flux to $\pm 10 \%$. Their results showed different requirements in each region; 24/year and $>70 /$ year in the Pacific and Mediterranean Sea, respectively.

[7] Sweeney et al. [2002] use two Southern Ocean northsouth transects (winter and summer) to determine the spatial sampling required to constrain the mean $\Delta \mathrm{pCO}_{2}$ to $\pm 4.3 \mu \mathrm{atm}$ (equating to a $\pm 0.1 \mathrm{PgC} / \mathrm{yr}$ for the Southern Ocean using a mean Southern Ocean gas exchange coefficient, south of $50^{\circ} \mathrm{S}$ ). They show that sampling every $5^{\circ}$ in latitude in the summer and $10^{\circ}$ latitude in the winter is required. Takahashi and Sweeney [2002] subsample global, gridded, monthly flux maps (extended from Takahashi et al. [1997]) to determine the sampling needed to capture the net annual $\mathrm{CO}_{2}$ flux. Subsampling the mean monthly flux maps, they suggest sampling three times per year is required, but did not develop a specific spatial sampling strategy for the Southern Ocean. Their analysis maybe biased as it assumes that the ocean is in steady state (for the year 1995) and ignores variability on timescales shorter than monthly.

[8] The goal of this work was to develop and validate a sampling strategy that reduces the uncertainty in the Southern Ocean annual uptake of $\mathrm{CO}_{2}$ to a target of $\pm 0.1 \mathrm{PgC} / \mathrm{yr}$. By using a time-evolving-prognostic-high-resolution-biogeochemical model to simulate the fluxes this paper has extended previous analyses by combining spatial and temporal sampling strategies. An accurate representation of the Southern Ocean $\mathrm{CO}_{2}$ uptake and its uncertainty provides: (1) the essential information to resolve the present mismatch between observational and model estimates of the uptake which will reduce the uncertainty in the global budget [Friedlingstein et al., 2003]; (2) a reference against which future changes in variability can be assessed; and (3) an observational estimate to assess and validate numerical models.

[9] In section 2 the prognostic biogeochemical ocean model and the observations used to assess the statistical characteristics of our simulated $\Delta \mathrm{pCO}_{2}$ fields are described. In section 3: (1) Fourier Transforms with signal-to-noise ratios have been used to investigate the temporal and spatial variability that dominates the simulated Southern Ocean $\mathrm{CO}_{2}$ air-sea fluxes; and (2) the sampling strategy required to resolve this variability has been developed. Our proposed sampling strategy and the current sampling were also used to estimate the Southern Ocean $\mathrm{CO}_{2}$ uptake. A strategy to obtain the necessary samples to estimate the Southern Ocean uptake of $\mathrm{CO}_{2}$ to $\pm 0.1 \mathrm{PgC} / \mathrm{yr}$ is discussed in section 4 .

\section{Methods}

\subsection{Modeling}

[10] To compensate for the lack of observed air-sea $\mathrm{CO}_{2}$ fluxes, a prognostic 3D Global Biogeochemical Ocean General Circulation Model (BOGCM) was used to simulate daily values of air-sea flux and $\Delta \mathrm{pCO}_{2}$. The ocean general circulation module (OGCM) of the BOGCM was based on the $\mathrm{Z}$ coordinate Modular Ocean Model (MOM) Version 3 [Pacanowski and Griffies, 1999]. The OGCM used the T63-2 grid, a grid spacing of $0.94^{\circ} \mathrm{N}-\mathrm{S}$ and $1.9^{\circ} \mathrm{E}-\mathrm{W}$, with 31 vertical levels, 15 levels in the upper $500 \mathrm{~m}$. To represent the effects of eddies not simulated in the model, the eddy 


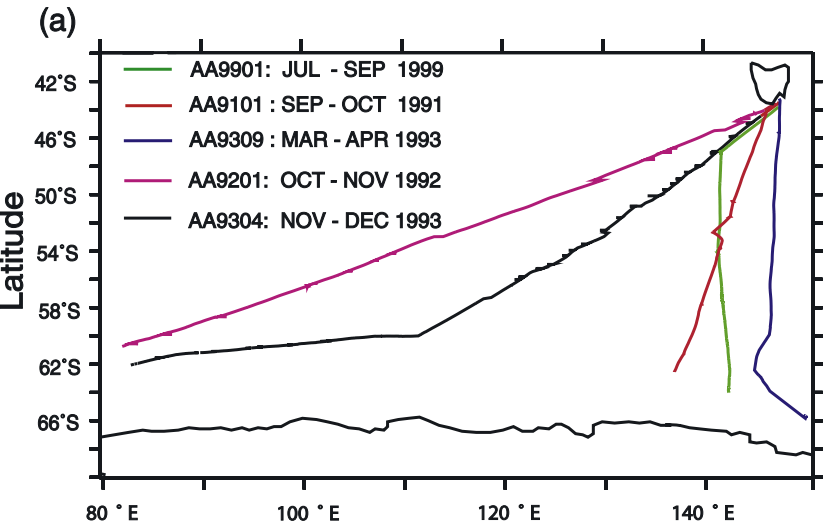

(b)

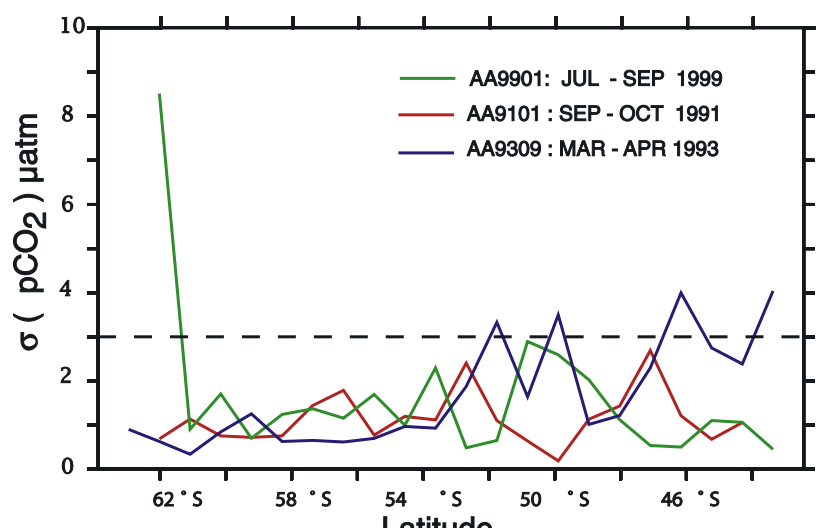

(c)

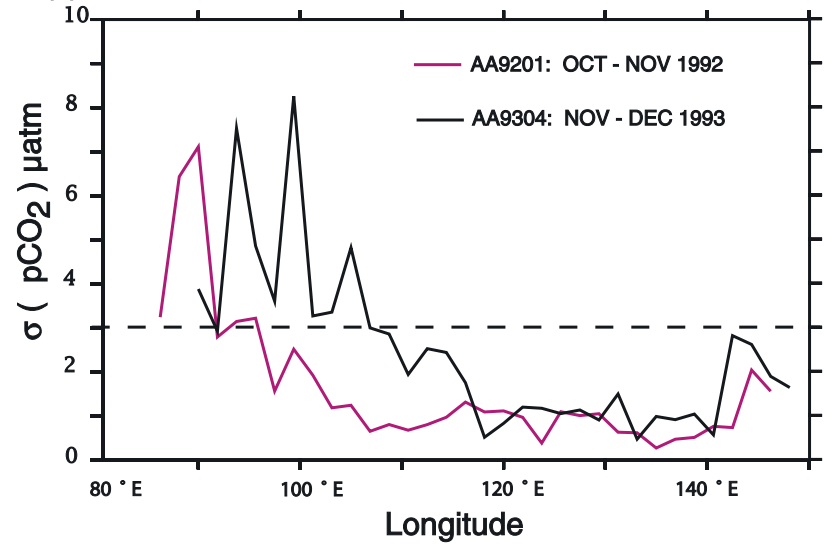

Figure 2. (a) The location of the observational data used to estimate the variability not captured by the model. $(\mathrm{b}, \mathrm{c})$ The standard deviation of the subgrid-scale variability in $\mathrm{pCO}_{2}$ not captured by the model resolution. The dashed line represents the $3-\mu \mathrm{atm}$ value.

parameterization of Gent and McWilliams [1990] was implemented, as was the Chen mixed layer scheme [Chen et al., 1994] to parameterize upper ocean mixing.

[11] The biogeochemical module of the BOGCM predicted DIC, alkalinity, oxygen and phosphate. A detailed description of the model is given by Matear and Hirst [1999] and Matear [2004]. Export production in the top $50 \mathrm{~m}$ was calculated as a function of light, nutrient concentration, temperature and mixed layer depth. $\mathrm{CaCO}_{3}$ production was set at $8 \%$ of the export production [Yamanaka and Tajika, 1996]. Below the euphotic zone, particulate organic matter and $\mathrm{CaCO}_{3}$ were remineralized as a function of depth according to $(\mathrm{z} / 100)^{-0.9}$ and $\mathrm{e}^{(-\mathrm{z} / 3500)}$ respectively [Yamanaka and Tajika, 1996]. Nutrient uptake and remineralization of P:N:C:O $\mathrm{O}_{2}$ were related via the Redfield ratio of 1:16:106:-138 in and below the euphotic zone [Redfield et al., 1963].

[12] The model was forced with daily wind stress, heat and freshwater fluxes from NCEP -R1 [Kalnay, 1996]. Seaice was not explicitly modeled, but the use of the NCEP -R1 implicitly included the effect of sea ice on heat and freshwater fluxes. The sea surface temperature and salinity were restored to observed sea surface temperatures (SST) [Reynolds and Smith, 1994] and sea surface salinity [Conkright et al., 2002] every 30 days. Air-sea gas exchange of $\mathrm{CO}_{2}$ was calculated following the short-term wind speed relationship of Wanninkhof [1992], using daily wind speed from NCEP-R1. To account for a lack of explicit sea ice, the net $\mathrm{CO}_{2}$ flux was scaled by the fraction of observed sea-ice cover, interpolated from the monthly climatological fields of Walsh [1978] and Zwally et al. [1983]. A net flux into the ocean was defined as positive.

[13] The model was initialized with the observed fields from Conkright et al. [2002] and evolved for $>4000$ years. Following this initial evolution the model had not yet reached quasi-steady state and so to ensure upper ocean dynamics were well captured, we reinitialized the temperature and salinity fields from Conkright et al. [2002] in accordance with the protocols of the Northern Ocean Carbon Exchange Study (NOCES)/Ocean Carbon Model Intercomparison Project 3 (OCMIP3) [Aumont et al., 2004]. The model was then evolved from 1837 to 2002 with observed atmospheric $\mathrm{pCO}_{2}$ values from Enting et al. [1994] (www.ipsl.jussieu.fr/OCMIP) in accordance with the protocols of NOCES/OCMIP3.

\subsection{Observations}

[14] In the development of a Southern Ocean sampling strategy, observed $\mathrm{pCO}_{2}$ data was used to characterize the spatial variability of $\mathrm{pCO}_{2}$ and to estimate model subgrid variability. Observational data chosen were from cruises in the Australian Sector of the Southern Ocean between $80^{\circ} \mathrm{E}$ and $160^{\circ} \mathrm{E}$ (Figure 2a) (B. Tilbrook, Observational measurements of $\mathrm{pCO}_{2}$ in the Australian sector of the Southern Ocean, CSIRO Marine and Atmospheric Research, personal communication, 2005).

[15] Observational $\mathrm{pCO}_{2}$ was measured from the seawater intake located approximately $5 \mathrm{~m}$ below the surface. The seawater was continually equilibrated with a closed loop of air using a "Weiss" type showerhead equilibrator [Metzl et al., 1999]. The $\mathrm{xCO}_{2}$ of the equilibrated air was dried and measured using a LICOR ${ }^{\circledR} 6252$ infrared gas analyzer. We used the following equation (equation (2)) from Dickson and Goyet [1994] to convert of $\mathrm{xCO}_{2}$ to $\mathrm{pCO}_{2}$; the vapor pressure of seawater $\left(\mathrm{Vp}\left(\mathrm{H}_{2} \mathrm{O}\right)\right)$ was calculated following Weiss and Price [1980] and the atmospheric pressure was measured on the ship.

$$
p C \mathrm{O}_{2}=x C \mathrm{O}_{2} \times P_{A T M}\left(1-\mathrm{Vp}\left(\mathrm{H}_{2} \mathrm{O}\right)\right)
$$


(a)

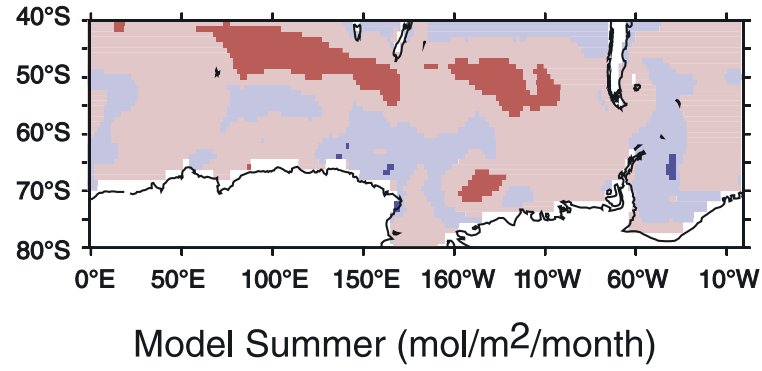

(b)

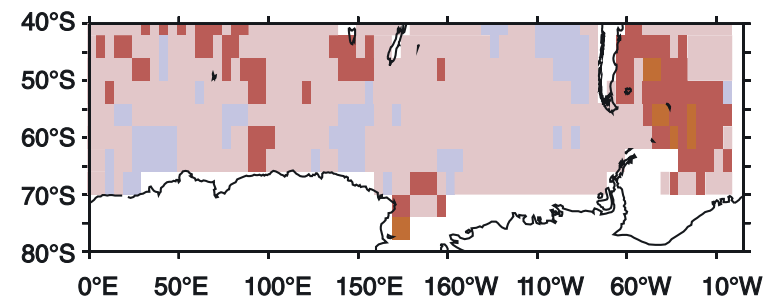

Takahashi et al. Summer (mol/m2/month) (c)

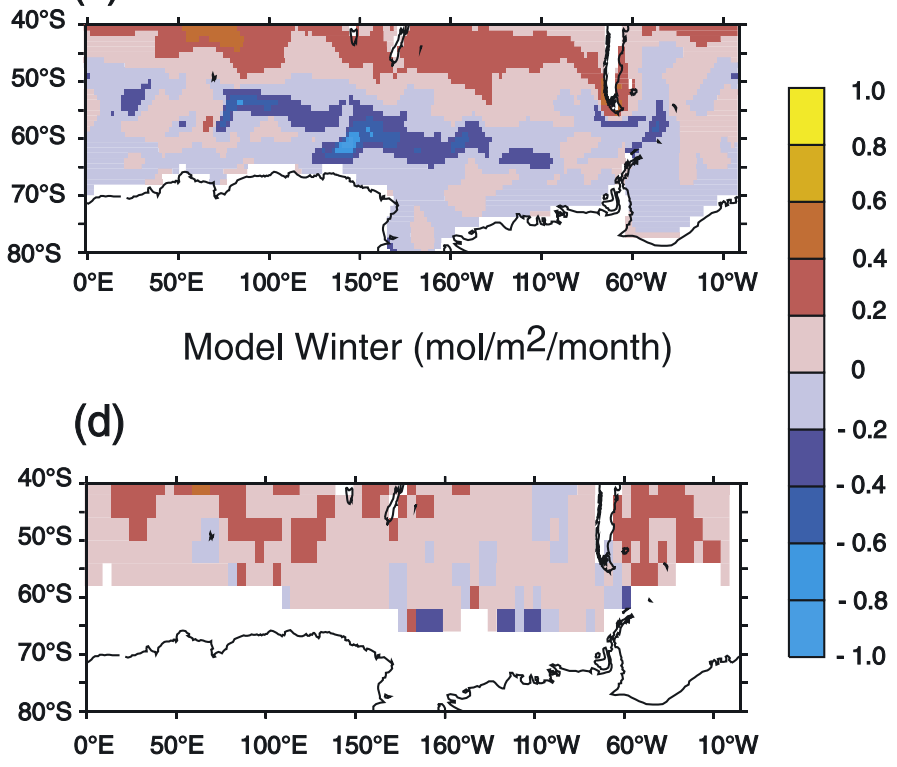

Takahashi et al. Winter ( $\left.\mathrm{mol} / \mathrm{m}^{2} / \mathrm{month}\right)$

Figure 3. Climatologically summer (Jan, Feb, Mar) and winter (Jul, Aug, Sept) air-sea $\mathrm{CO}_{2}$ fluxes ( $\mathrm{mmol} / \mathrm{m}^{2} / \mathrm{month}$ ); Simulated fluxes (top) from the CSIRO model and (bottom) from Takahashi et al [2002]. Note that positive flux is into the ocean.

[16] The measured warming of less than $1^{\circ} \mathrm{C}$ between the intake and the equilibrator was corrected following CopinMontégut [1988, 1989]. Surface $\mathrm{pCO}_{2}$ was calibrated against three reference samples every 6 hours. Prior to 1997, data was collected every $4 \mathrm{~min}$, and thereafter every minute. On the basis of intercomparisons of the system [Körtzinger et al., 2000] and the comparison of air-samples taken at monitoring sites including Cape Grim, Macquarie Island and Mawson Antarctic Base [Francey et al., 2003], the accuracy and precision of $\mathrm{pCO}_{2}$ was considered to be better than $\pm 2 \mu$ atm.

[17] To account for the subgrid-scale variability, which was not captured by our coarse-resolution model simulation, we used the observed variability in the $\mathrm{pCO}_{2}$ data. These high-resolution cruise data (Figure 2a) were first binned by the latitudinal and longitudinal resolution of the model and the standard deviation of the subgrid variability was then calculated (Figures $2 \mathrm{~b}$ and $2 \mathrm{c}$ ). We estimated that a normal distribution with a standard deviation of $3 \mu \mathrm{atm}$ was adequate to represent the Southern Ocean subgrid-scale variability. We note that by using a normal distribution we may have slightly underestimated the large changes in $\Delta \mathrm{pCO}_{2}$ observed in the seasonal sea ice zone, but may have overestimated the open ocean variability.

\section{Results and Discussion}

\subsection{Model Analysis}

[18] To better represent the observed variability in the Southern Ocean we defined our simulated $\Delta \mathrm{pCO}_{2}$ and air-sea $\mathrm{CO}_{2}$ flux as the combination of modeled and subgrid-scale variability. In accordance with the observed subgrid-scale variability, we estimated a randomly generated normal distribution with a standard deviation of $3 \mu \mathrm{atm}$ which was adequate to represent this variability. We added this subgrid-scale variability directly to the modeled $\triangle \mathrm{pCO}_{2}$. For the air-sea $\mathrm{CO}_{2}$ flux, this variability was first multiplied by the daily gas exchange co-efficient (equation (1)) and then added to the modeled air-sea $\mathrm{CO}_{2}$ flux.

[19] Sparse Southern Ocean sampling meant that existing observational data were too limited (Figure 1) to comprehensively assess the simulated air-sea $\mathrm{CO}_{2}$ fluxes. Instead we separated the simulated air-sea $\mathrm{CO}_{2}$ flux variability into seasonal and nonseasonal variability. The seasonal cycle was defined as the daily (climatological) air-sea flux of $\mathrm{CO}_{2}$ over the 1990-1999 period. The nonseasonal variability was defined as the simulated air-sea flux not represented by the seasonal cycle.

[20] The simulated seasonal cycle was compared to the coarse-resolution, monthly climatological maps of Takahashi et al. [2002]. The summer (Jan-Mar) and winter (Jul-Sept) comparison showed that the simulated seasonal cycle captured much of the large-scale variability that exists in the Southern Ocean observations (Figures $3 a-3 d$ ). The major differences between the simulated seasonal cycle and observations were evident in: (1) the Southern Atlantic Ocean where the simulated ocean was a weak source (outgassing) of $\mathrm{CO}_{2}$, while the observations showed it to be a strong $\mathrm{CO}_{2}$ sink (uptake); (2) the Subantarctic region where the simulated fluxes showed a larger winter sink of $\mathrm{CO}_{2}$ than the observations; and (3) in the region $50^{\circ} \mathrm{S}-60^{\circ} \mathrm{S}$ where the simulated fluxes showed a stronger winter source of $\mathrm{CO}_{2}$ than the observations. These differences may reflect the limited data coverage of Takahashi et al. [2002]. 


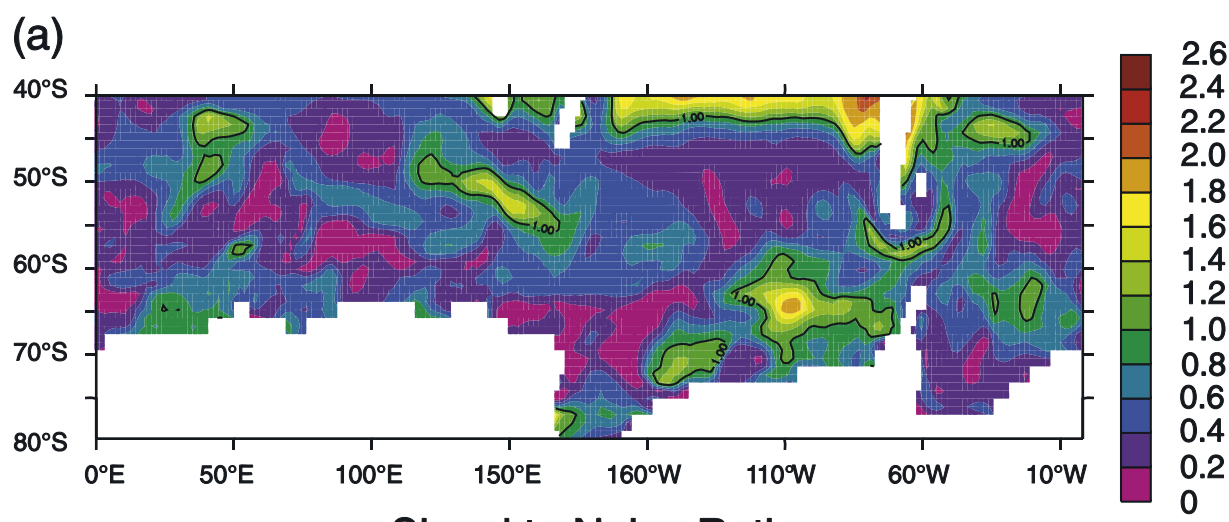

(b) Signal to Noise Ratio

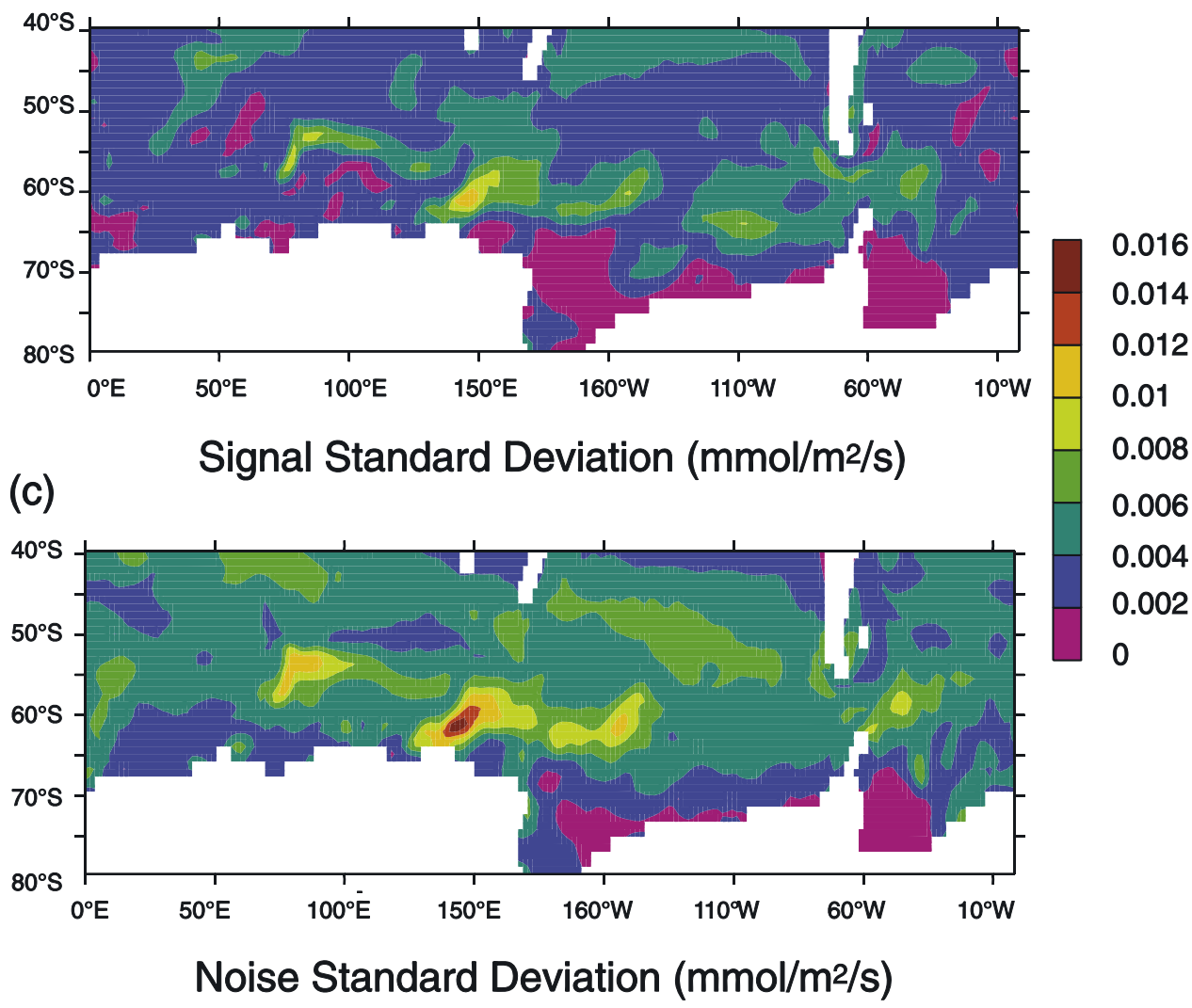

Figure 4. (a) SNR map of the air-sea fluxes of $\mathrm{CO}_{2}$ in the Southern Ocean, a contour level representing a SNR of 1 is marked. (b) The standard deviation of the signal. (c) The standard deviation of the noise.

[21] To assess the air-sea flux variability in the Southern Ocean, signal-to-noise ratios (SNR) were calculated following Ballabrera-Poy et al. [2003] and Schiller et al. [2004], where $\sigma^{2}$ denotes variance. We define the seasonal cycle to be the signal and the nonseasonal variability as the noise.

$$
S N R=\frac{\sigma_{S I G N A L}^{2}}{\sigma_{\text {NOISE }}^{2}}=\frac{\sigma_{\text {SIGNAL }}^{2}}{\sigma_{A L L D A T A}^{2}-\sigma_{\text {SIGNAL }}^{2}}
$$

[22] To assess the relative magnitude of the temporal variability in the signal and noise we computed a SNR map for the daily simulated air-sea $\mathrm{CO}_{2}$ fluxes (1990-1999; Figure 4a). Over most of the Southern Ocean the SNR was less than 1. In these locations it would be difficult observationally, using the 10 years of daily modeled air-sea fluxes, to separate the seasonal cycle variability from the large non-seasonal variability. The maps of the standard deviation $(\sigma)$ of the signal and noise are shown in Figures $4 \mathrm{~b}$ and $4 \mathrm{c}$. Figure $4 \mathrm{~b}$ showed that the variability in the seasonal flux was not homogenous, consistent with the Takahashi et al. [2002] climatology.

[23] What sampling was required to constrain the Southern Ocean air-sea $\mathrm{CO}_{2}$ flux given the large variability observed in the model? Two-dimensional Fourier Transforms (2D-FT) in space and time along sections of constant latitude (east-west) and longitude (north-south) were used to 


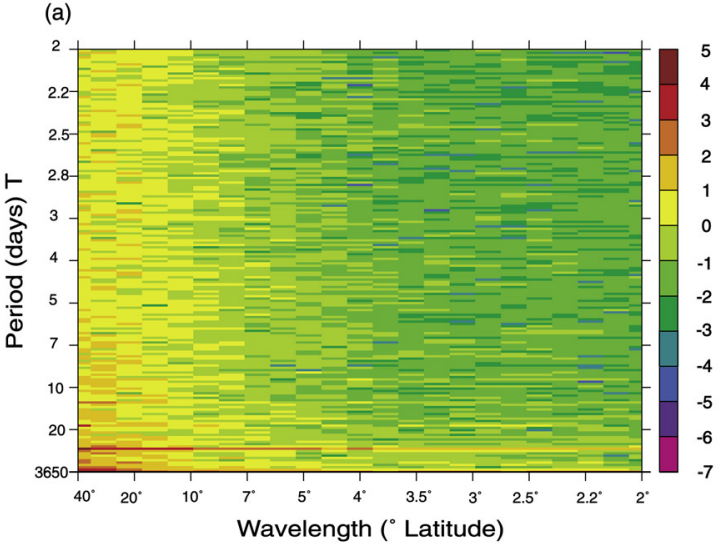

(b)

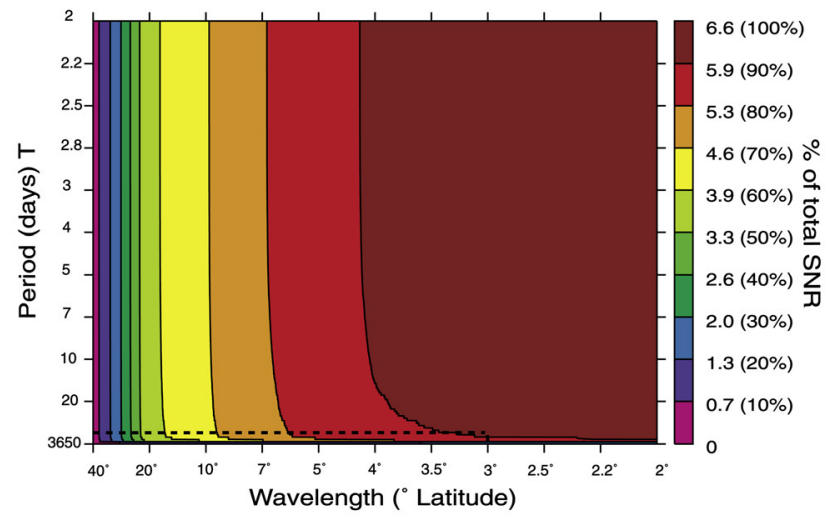

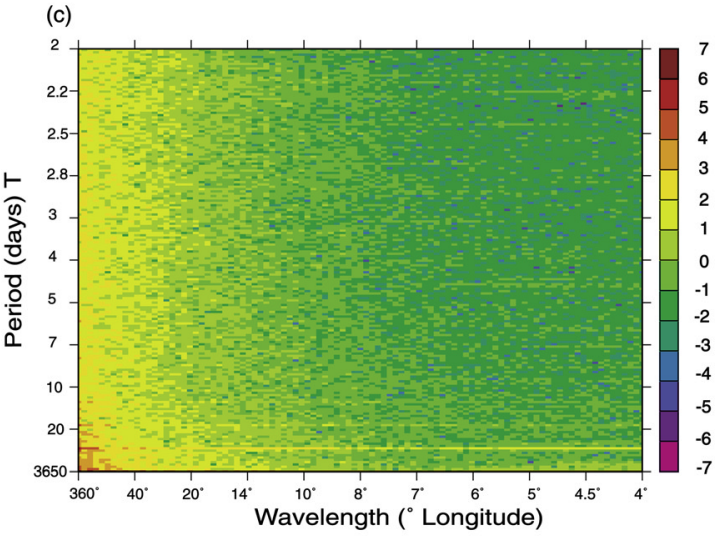

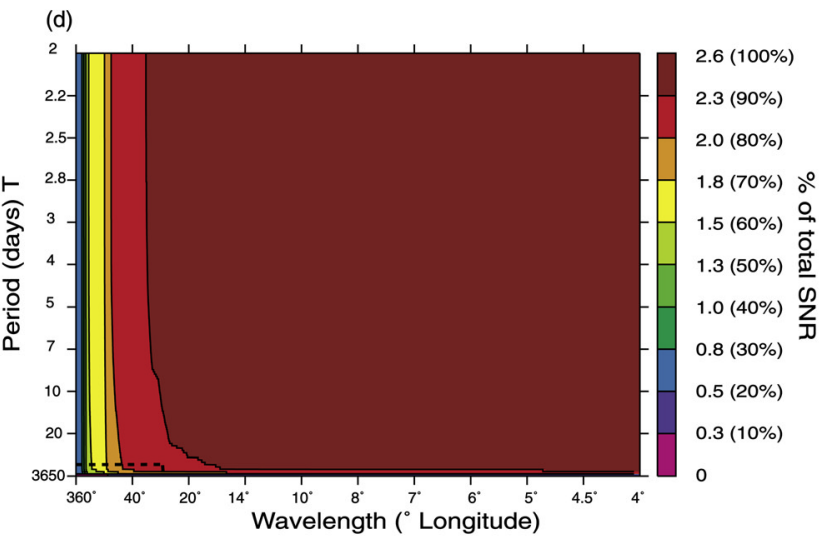

Figure 5. (a, c) The log 2D Fourier transform in space and time of longitudinally (north-south) and latitudinally (east-west) averaged air-sea fluxes in the Southern Ocean (south of $40^{\circ} \mathrm{S}$ ). (b, d) SNR contour plots in the frequency domain of the data in Figures 5a and 5c, respectively. The sampling point is shown as the intersection of the dashed lines. Please refer to the text for an explanation.

characterize the spectrum of the simulated flux variability south of $40^{\circ} \mathrm{S}$.

[24] Figures 5a and 5c show the log of the variance of the 2D-FT of air-sea flux averaged in latitude (north-south) and in longitude (east-west) in the Southern Ocean. These figures revealed that: (1) the Southern Ocean is a net uptake region, i.e., a non-zero value when the wavelength $(\lambda)$ was zero and the period (T) was equal to the record length (i.e., infinite); (2) at long wavelengths $\left(\lambda>5^{\circ}\right)$ there was a more uniform spread of variability across a range of periods; and (3) there was rapid decline in the amount of variance explained by short periods $\mathrm{T}<20$ days and short wavelengths $\lambda<5^{\circ}$.

[25] We applied Parseval's Theorem to derive a new relationship for SNR in the frequency domain (equation (4)) that is equal to the SNR in the temporal domain (equation (3)); see Appendix A. This new SNR describes the variance explained as a function of frequency.

$$
\operatorname{SNR}(f)=\frac{\sum_{n=1}^{f} H_{\text {signal }}(n)^{2}}{\sum_{n=1}^{f} H_{\text {noise }}(n)^{2}}
$$

[26] Equation (4) was applied to the 2-D Fourier Transform of the air-sea fluxes to investigate how the SNR changed, as higher temporal and spatial sampling frequencies were resolved. Figures $5 \mathrm{~b}$ and $5 \mathrm{~d}$ show the SNR of latitudinally (east-west) and longitudinally (north-south) averaged air-sea fluxes in the frequency domain. We interpret these figures as the SNR resolved at different sampling frequencies in time and space. The upper right-hand corner represented the maximum SNR by sampling at the model resolution.

[27] Once the seasonal cycle is resolved, the amount of variance explained does not continue to increase appreciably. The SNR is shown to asymptote in time and space, as illustrated by the straight vertical and horizontal lines in the contour plots of SNR (Figures $5 \mathrm{~b}$ and $5 \mathrm{~d}$ ). The most efficient way to increase SNR, after the seasonal cycle has been resolved, is to increase the spatial sampling. Figures $5 \mathrm{~b}$ and $5 \mathrm{~d}$ also demonstrated that high resolution in time and low resolution in space or high resolution in space and low resolution in time returns a SNR value that is less than $20 \%$ of the maximum value. This was consistent with Figure 4a in which high temporal (daily) sampling and poor spatial sampling produces a SNR of $<1$. 

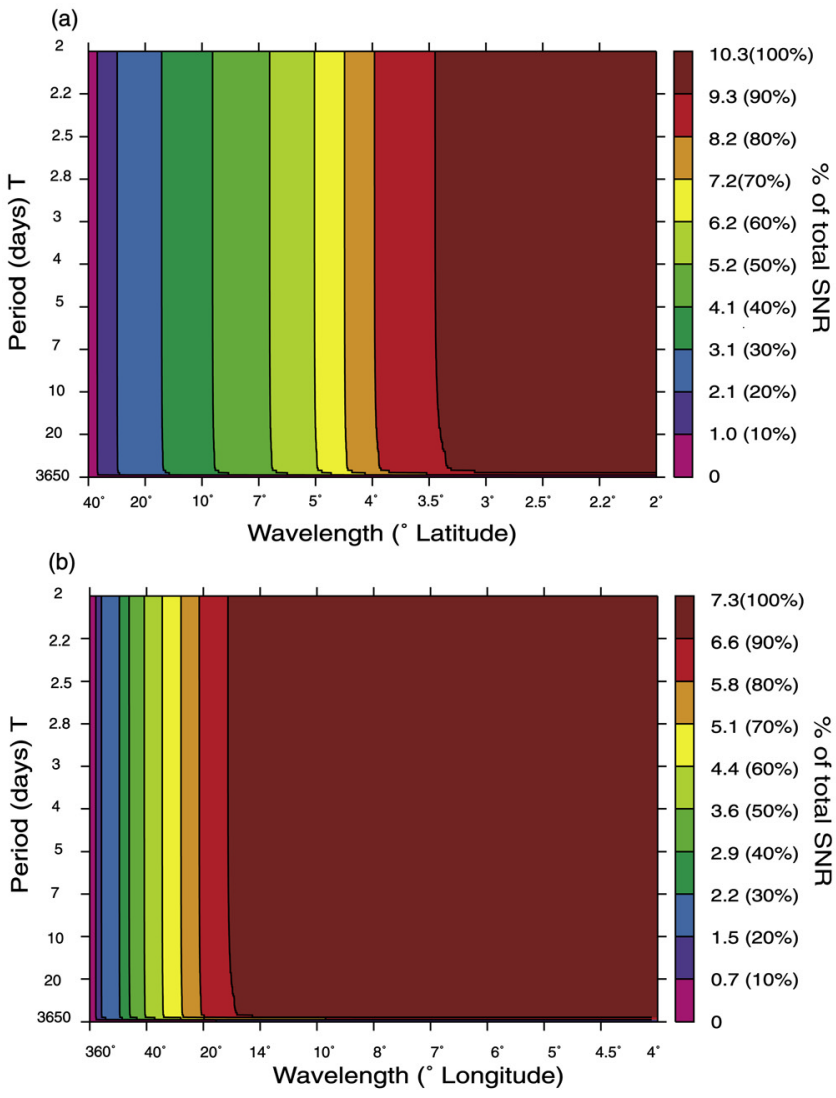

Figure 6. $\triangle \mathrm{pCO}_{2} \mathrm{SNR}$ contour plots in the frequency domain of (a) longitudinally and (b) latitudinally averaged simulated values in the Southern Ocean (south of $40^{\circ} \mathrm{S}$ ). Please refer to the text for an explanation.

[28] A sampling strategy for the net air-sea flux of $\mathrm{CO}_{2}$ that returns the maximum SNR value is ideal. However, with limited sampling resources a strategy was required that best reflected the tradeoff between a realistic sampling effort and an acceptable SNR value. We suggest the optimum sampling is the point where the SNR starts to asymptote, i.e., where we can maximize SNR with minimum sampling. From Figure 5b, sampling every $3^{\circ}$ in latitude, every 3 months ( $\sim 91$ days) would capture greater than $90 \%$ of the maximum SNR. A north-south sampling of every $3^{\circ}$ corresponds to approximately 12 samples between $40^{\circ} \mathrm{S}$ and the Antarctic Continent. From Figure 5d sampling every $30^{\circ}$ in longitude, every 3 months ( $\sim 91$ days) would return more than $85 \%$ of the maximum SNR.

[29] Figure 5b demonstrates that averaging over zonal (north-south) bands, significantly improves the SNR value to 6.6, which is much greater than any point in Figure 4a. This increase in SNR reflects a much greater reduction in the noise than the signal when averaging zonally because the signal is more correlated zonally than the noise. In contrast, no significant improvement in optimal SNR value (2.6) occurs when we average meridionally (east-west).

[30] Figures $6 \mathrm{a}$ and $6 \mathrm{~b}$ showed the SNR analyses for $\triangle \mathrm{pCO}_{2}$ and that regular sampling every three months at spatial grid of $3^{\circ}$ in latitude and $30^{\circ}$ in longitude returned more than $70 \%$ of the maximum SNR value. This was very similar to the maximum SNR returned from air-sea fluxes. From equation (1), any difference in the response between $\mathrm{pCO}_{2}$ and air-sea $\mathrm{CO}_{2}$ flux is the gas transfer coefficient. The similarity in sampling requirements between $\triangle \mathrm{pCO}_{2}$ and air-sea $\mathrm{CO}_{2}$ flux suggests that it is the longer wavelength changes in $\triangle \mathrm{pCO}_{2}$ that are more important in determining the seasonal fluxes than short-term (high frequency) variability in the gas exchange coefficient.

\subsection{Statistical Model Validation}

[31] There were not enough observations in the Southern Ocean to validate our sampling strategy directly. We looked instead at the statistical properties of the observations and show these are both consistent with the model and our proposed sampling strategy. As the proposed sampling strategy of $\triangle \mathrm{pCO}_{2}$ is very similar to that for the $\mathrm{CO}_{2}$ airsea flux, we only compare $\Delta \mathrm{pCO}_{2}$ from the model with the observations. To aid in the comparison of the statistical properties of the simulated and observed fluxes, the nonzero, i.e., mean uptake from both the observations and simulated values, were removed.

[32] Figure 7a shows the normalized cumulative $\Delta \mathrm{pCO}_{2}$ power spectra from three north-south transects, traveling during the austral winter (AA9901), summer (AA9101) and spring (AA9309) between Tasmania $\left(43^{\circ} \mathrm{S}\right)$ and Antarctica $\left(66^{\circ} \mathrm{S}\right)\left(\sim 140^{\circ} \mathrm{E}\right)$ (Figure $\left.2 \mathrm{a}\right)$. We have overlain on this plot, the modeled power spectrum corresponding to these transects in time and location. Note the Nyquist frequency from our model was $1.9^{\circ}$, which was much greater than the observations $\left(0.2^{\circ}\right)$. Like the simulated field, the observations had most of the variance in long wavelengths with $\lambda>3^{\circ}$ capturing more than $90 \%$ of the total variance in the observations. We also saw that the variability that occurs on spatial scales less than what the model resolves $\left(2^{\circ}\right)$ represented less than $5 \%$ of the observed variability. Therefore, from the observational data, we concluded the variability was dominated by long wavelengths consistent with the model and that the subgrid-scale variability not represented in the model did not significantly alter our analysis.

[33] Figure $7 \mathrm{~b}$ shows the normalized cumulative $\Delta \mathrm{pCO}_{2}$ power spectra from three east-west transects traveling between $\sim 80^{\circ}$ and $\sim 150^{\circ} \mathrm{E}$. These cruises took place in the Austral summer (AA9304) and spring (AA9201) (Figure 2a). Overlain on this plot are the power spectra of the modeled transects, corresponding to the same time and location. The longitudinal Nyquist Frequency from our model was $3.8^{\circ}$, which was much greater than the Nyquist frequency of the observations. The lack of good agreement with the observations may have been due to the ship tracks not being truly east-west. The observations did however suggest more than $90 \%$ of the variance was captured by $\lambda>3^{\circ}$ in longitude. These results suggest the variability was dominated by long wavelengths consistent with the model; hence our model resolution of $1.9^{\circ}$ in longitude was adequate to capture the statistical characteristics of the observations. 
(a)
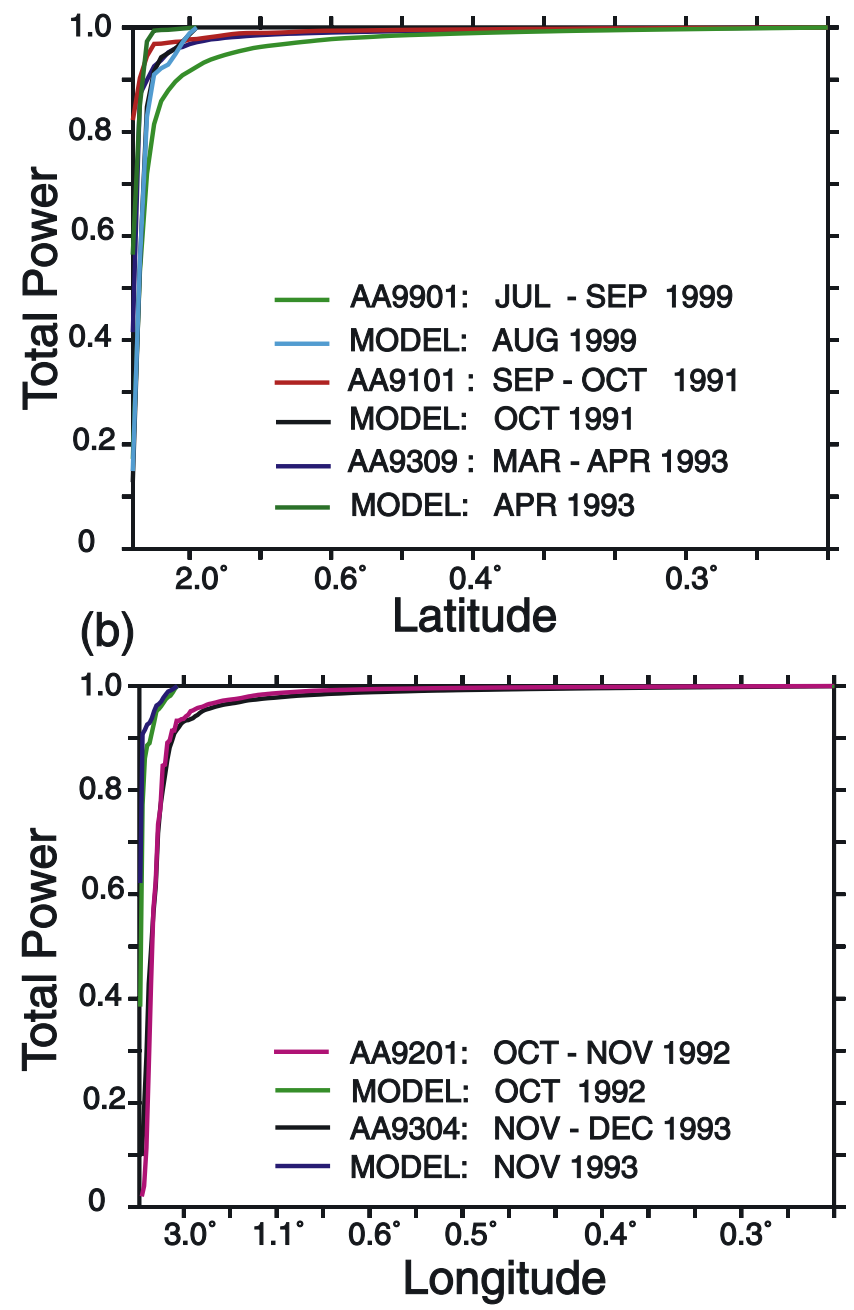

Figure 7. (a) Cumulative variance plots of $\Delta \mathrm{pCO}_{2}$ from two observed transects traveling N-S and the corresponding model transects. (b) Cumulative variance plots of $\Delta \mathrm{pCO}_{2}$, from observed transects traveling E-W (longitude) and the corresponding model transects.

\subsection{Sensitivity of $\mathrm{CO}_{2}$ Uptake}

[34] To explore how well our sampling strategy performed and to quantify the uncertainty of our estimated annual mean uptake, we applied our sampling strategy to the simulated daily fluxes for each modeled year between 1990 and 1999. We calculated the simulated annual mean uptake to be $0.6 \pm 0.1 \mathrm{PgC} / \mathrm{yr}$ at the resolution of the model (Table 1, column 1). The uncertainty was calculated as $2 \sigma_{\overline{\text { Interannual }}}=2 \sigma_{\overline{\text { Interannual }}} / \sqrt{10}$ where $\sigma$ was the variance about the annual mean uptake. The uncertainty in the annual net uptake for the 1990s reflected the magnitude of the simulated interannual variability and was similar to the value reported by Wetzel et al. [2005] in the region between $40^{\circ} \mathrm{S}$ and $60^{\circ} \mathrm{S}(2 \sigma)$.

[35] Applying our sampling strategy, i.e., subsampling every $30^{\circ}$ in longitude and $3^{\circ}$ in latitude every 3 months, to our simulated air-sea fluxes, gave more than $4000\left(360^{\circ} \%\right.$ $30^{\circ} \times 30^{\circ} / 3^{\circ} \times 365 / 91$ days) realizations (grids) per year. Subsampling can change the surface area sampled. Thus, to ensure that the fluxes calculated for each grid could be compared, the air-sea flux was calculated in flux $/ \mathrm{m}^{2}$ and then multiplied by the Southern Ocean surface area. The annual mean uptake and uncertainty that were calculated for the 1990 s by applying our sampling strategy are summarized in Table 1 (column 2).

[36] We applied our sampling strategy to the simulated fluxes and returned a sampling uncertainty (from $>4000$ permutations/yr) of $\pm 0.2 \mathrm{PgC} / \mathrm{yr}(2 \sigma)$ for the Southern Ocean uptake, for any year in the 1990-1999 period (Table 1, column 3). This uncertainty level in uptake translates to a global mean oceanic uptake error of approximately $\pm 10 \%$. For the 1990 s, the estimated sampling error was $\pm 0.07 \mathrm{PgC} / \mathrm{yr}\left(2 \sigma_{\overline{\text { Sampling }}}=2 \sigma_{\overline{\text { Sampling }}} / \sqrt{10}\right)$.

[37] The annual mean uptake from our sampling strategy was systematically less, as seen in Table 1 (column 2), than the total simulated value (column 1). This was due to the bias introduced to the sampling estimate by starting our $3^{\circ}$ latitudinal sampling at either $40^{\circ}, 41^{\circ}$ or $42^{\circ}$. The mean values of the annual air-sea fluxes decrease as a function of increasing the latitude $\left(40^{\circ}\right.$ to $\left.42^{\circ}\right)$. This error can be as large as $\pm 0.1 \mathrm{PgC} / \mathrm{yr}$ and was included in the sampling error. If we sample our model at every degree N-S, we remove this bias from the estimated uptake, but do not change the estimate of the sampling uncertainty.

[38] The value of interannual variability returned by applying our sampling strategy in the Southern Ocean was $\pm 0.1 \mathrm{PgC} / \mathrm{yr}$ (1990-1999), which is the same value as calculated by sampling at the resolution of the model. Our results showed that even sampling at the maximum model resolution during the 1990-1999 period, would not improve the flux estimate beyond $\pm 0.1 \mathrm{PgC} / \mathrm{yr}$.

[39] To estimate the total uncertainty we combined our sampling error with the uncertainty due to interannual variability. We assumed these errors were independent and added these accordingly $\left(2 \sigma_{\overline{\text { Total }}}=\sqrt{\left.(2 \sigma) \frac{2}{\text { Interannual }}+(2 \sigma) \frac{2}{\text { Sampling }}\right)}\right.$ to estimate an annual averaged uptake for the 1990s of $0.6 \pm$ $0.1 \mathrm{PgC} / \mathrm{yr}$.

Table 1. Comparison of the Total Simulated Uptake With the Uptake From Our Proposed Sampling and the Sampling Error Introduced $^{\mathrm{a}}$

\begin{tabular}{lccc}
\hline Year & $\begin{array}{r}\text { Total Simulated } \\
\text { Uptake, PgC/yr) }\end{array}$ & $\begin{array}{c}\text { Sampled Estimate } \\
\text { of Uptake, PgC/yr }\end{array}$ & $\begin{array}{c}\text { Sampling Uncertainty } \\
(2 \sigma), \mathrm{PgC} / \mathrm{yr}\end{array}$ \\
\hline 1990 & 0.67 & 0.63 & 0.21 \\
1991 & 0.76 & 0.73 & 0.17 \\
1992 & 0.99 & 0.97 & 0.21 \\
1993 & 0.71 & 0.67 & 0.24 \\
1994 & 0.56 & 0.52 & 0.18 \\
1995 & 0.54 & 0.49 & 0.22 \\
1996 & 0.53 & 0.49 & 0.20 \\
1997 & 0.49 & 0.44 & 0.24 \\
1998 & 0.38 & 0.32 & 0.26 \\
1999 & 0.40 & 0.32 & 0.22 \\
$1990-1999$ & $0.60 \pm 0.12$ & $0.56 \pm 0.13$ & \\
\hline
\end{tabular}

${ }^{\mathrm{a}}$ Please refer to the text for an explanation. Estimates are of the Southern Ocean (south of $40^{\circ} \mathrm{S}$ ). 
Table 2. Comparison of the Total Simulated Uptake With the Uptake From the Current Sampling and the Sampling Error Introduced $^{\mathrm{a}}$

\begin{tabular}{lccc}
\hline Year & $\begin{array}{c}\text { Total Simulated } \\
\text { Uptake, PgC/yr }\end{array}$ & $\begin{array}{c}\text { Sampled Estimate } \\
\text { of Uptake, PgC/yr }\end{array}$ & $\begin{array}{c}\text { Sampling Uncertainty } \\
(2 \sigma), \text { PgC/yr }\end{array}$ \\
\hline 1990 & 0.67 & 0.67 & 0.37 \\
1991 & 0.76 & 0.77 & 0.33 \\
1992 & 0.99 & 1.0 & 0.42 \\
1993 & 0.71 & 0.72 & 0.42 \\
1994 & 0.56 & 0.55 & 0.38 \\
1995 & 0.54 & 0.54 & 0.36 \\
1996 & 0.53 & 0.53 & 0.36 \\
1997 & 0.49 & 0.49 & 0.42 \\
1998 & 0.38 & 0.38 & 0.37 \\
1999 & 0.40 & 0.40 & 0.38 \\
$1990-1999$ & $0.60 \pm 0.12$ & $0.61 \pm 0.12$ & \\
\hline
\end{tabular}

${ }^{\text {a}}$ Please refer to the text for an explanation. Estimates are of the Southern Ocean (south of $40^{\circ} \mathrm{S}$ ).

[40] The uncertainty calculated when we combined our sampling and interannual variability error estimates was the same as that calculated by sampling at the resolution of the model. This result suggested: (1) the uncertainty introduced when we applied our sampling strategy was small compared to the uncertainty due to interannual variability; and further that (2) sampling at a higher resolution that our proposed sampling would not improve the large-scale regional flux estimates.

[41] We repeated this sensitivity study, with the subgridscale variability calculated from the observations removed. This second analysis showed no change in the annual mean estimate and offered no significant improvement in the sampling error $(<0.002 \mathrm{PgC} / \mathrm{yr})$. These results suggested that the non-seasonal variability was being driven by longer wavelength changes such as interannual variability rather than mesoscale (subgrid scale) variability.

\subsection{Sensitivity Test of the Present Sampling Strategy}

[42] To assess the uncertainty of the present Southern Ocean sampling effort on the annual uptake of $\mathrm{CO}_{2}$ we used the observational effort shown in Figure 1 to approximate the current sampling effort. From Figure 1 there appear to be five north-south sections in the Southern Ocean $\left(\sim 60^{\circ} \mathrm{E}\right.$, $\left.120^{\circ} \mathrm{E}, 180^{\circ} \mathrm{E}, 60^{\circ} \mathrm{W}\right)$, which are repeated several times a year. We added one more section along $120^{\circ} \mathrm{W}$, to approximate additional one-time observations; this allowed Southern Ocean spatial coverage close to every $60^{\circ}$ in longitude. We also assumed that this sampling was completed regularly four times per year (i.e., adequate data coverage in the winter). This was an overestimate of the actual seasonal coverage since there are few observations in the winter season. We chose also to sample every degree in latitude to better represent ship-based measurements. We do not believe this sampling improves on the present sampling of the Southern Ocean but it does provide a useful assessment of the uncertainty in the Takahashi et al. [2002] Southern Ocean uptake estimate and an estimate of the uncertainty achievable using the present sampling effort.

[43] Reapplying our sensitivity analysis from section 3.3 to this new, coarser sampling grid, the uncertainty in the uptake for any year in the $1990 \mathrm{~s}$ was $\pm 0.4 \mathrm{PgC} / \mathrm{yr}(2 \sigma)$ (Table 2). These results are derived from more than 2700 grid permu- tations $/ \mathrm{yr}\left(360^{\circ} / 60^{\circ} \times 30^{\circ} / 1^{\circ} \times 365 / 91\right.$ days $)$. This sensitivity analysis showed that halving the proposed longitudinal (east-west) sampling doubled the error owing to sampling.

[44] Approximating the current Southern Ocean sampling, interannual variability was estimated to be $\pm 0.1 \mathrm{PgC} / \mathrm{yr}$ (1990-1999; column 2). Combining interannual variability with the calculated sampling error (Table 2, column 3) we estimated the annual uptake for the Southern Ocean to be $0.6 \pm 0.2 \mathrm{PgC} / \mathrm{yr}(1990-1999)$. The error introduced by the present sampling was double the error of our recommended strategy. Taking into account our initial assumptions of data and seasonal coverage, the error estimate of $\pm 0.2 \mathrm{PgC} / \mathrm{yr}$ can be considered a lower bound uncertainty of the Takahashi et al. [2002] estimate of the Southern Ocean $\mathrm{CO}_{2}$ uptake for the 1990s.

\subsection{Comparison With Other Studies}

[45] We compare our sampling strategy to those published by Garçon et al. [1992] and Mémery et al. [2002]. Both these studies used high-resolution 1-D time series data of air-sea $\mathrm{CO}_{2}$ fluxes to recommend temporal sampling of 24 and $>70$ annually (respectively). The findings of Garçon et al. [1992] and Mémery et al. [2002] are consistent with the results shown in Figures $5 \mathrm{~b}$ and $5 \mathrm{~d}$. These figures demonstrate that for a very small wavelength $(\lambda)$, i.e., sampling spatially at very few points, the increase in SNR is small with increasing temporal resolution: therefore many temporal samples are needed to maximize the SNR.

[46] Sweeney et al. [2002] using Southern Ocean observations along $170^{\circ} \mathrm{W}$, suggested sampling every $\sim 2.5^{\circ}$ of latitude in summer and every $\sim 7.5^{\circ}$ of latitude in winter. Their sampling strategy was based on determining the number of samples required to constrain the mean $\Delta \mathrm{pCO}_{2}$ to within $\pm 4.3 \mu \mathrm{atm}$ (equating to an uncertainty of $\pm 0.1 \mathrm{PgC} / \mathrm{yr}$ over the entire Southern Ocean). Although they use a different criterion for determining the required sampling, their results based on Southern Ocean observations are consistent with our analysis of the simulated fluxes. The agreement further supports the assertion that the model does simulate the spectral characteristics of the observations and the model-derived sampling strategy is applicable to the real ocean.

[47] Takahashi and Sweeney [2002] explored the uncertainty introduced by subsampling in time and space, the coarse resolution $\left(4^{\circ} \times 5^{\circ}\right)$ monthly climatological maps of air-sea flux of $\mathrm{CO}_{2}$ (extended from Takahashi et al. [1997]). Although Takahashi and Sweeney [2002] did not identify specific Southern Ocean sampling requirements, their global analysis suggests that measurements every three months is sufficient to determine the net $\mathrm{CO}_{2}$ air-sea flux. They saw no significant improvement in the basinscale net air-sea flux by increasing temporal sampling. Although the monthly climatological data does not include variability on timescales of less than a month, their results are consistent with our conclusion that most of the variance in the signal of the air-sea fluxes is resolved by 3-monthly sampling.

[48] Our sampling strategy suggests different sampling requirements when moving zonally (east-west) and meridionally (north-south) through our study area, consistent with 
the results of Takahashi and Sweeney [2002]. Our sampling strategy is also consistent with the results of Sweeney et al. [2002] and Takahashi and Sweeney [2002], who demonstrated that regular sampling, spatially and temporally, produced better flux estimates than irregular sampling. A comprehensive understanding of the spatial and temporal characteristics of the real ocean would be needed to allow an irregular sampling approach to be exploited.

\section{Conclusion}

[49] We used a BOGCM model simulation driven by NCEP-R1 forcing in conjunction with subgrid-scale estimates of variability to investigate the sampling required to constrain annual uptake in the 1990s of $\mathrm{CO}_{2}$ by the Southern Ocean. The results showed that a regular threemonthly sampling every $30^{\circ}$ in longitude and $3^{\circ}$ in latitude would return the annual mean air-sea $\mathrm{CO}_{2}$ flux to within $\pm 0.1 \mathrm{PgC}$.

[50] The comparison between observations and the model suggests that the model does represent the statistical properties of the real ocean and captures much of the large-scale variability that exists in the Southern Ocean. A more complex biological model or higher resolution model may better represent high-frequency, nonseasonal variability but would not change the accuracy or precision of the largescale flux estimates. However, this result is specific to resolving the large-scale fluxes, and finer-scale sampling may be important for understanding biogeochemical cycling and its drivers.

[51] The proposed sampling of $\Delta \mathrm{pCO}_{2}$ was independent of the error due to uncertainty in gas transfer in air-sea $\mathrm{CO}_{2}$ fluxes. Therefore the equivalence between the sampling strategies for air-sea $\mathrm{CO}_{2}$ flux and for $\Delta \mathrm{pCO}_{2}$, suggest that the strategy we developed is independent of the uncertainty in gas transfer. As the uncertainty in gas transfer can be very large [e.g., Nightingale et al., 2000] it is important that the uncertainty calculated by implementing our sampling strategy account for the (additional) uncertainty due to gas transfer.

[52] The goal of determining the Southern Ocean net seasonal air-sea flux to within the natural variability of the system is achievable by augmenting the existing measurements to improve data coverage. The opportunities to make measurements in the Southern Ocean are limited and a number of platforms need to be utilized, including additional underway ship observations, time series moorings and potentially, the use of $\mathrm{CO}_{2}$ sensors mounted on drifters or profiling floats. An example is the development of a $\mathrm{CO}_{2}$ sensor on a profiling drifter like $A R G O$ [Gould et al., 2004] to utilize its spatial coverage. $A R G O$ drifters have a proposed coverage of $3^{\circ} \times 3^{\circ}$ globally [ARGO Science Team, 1998]; only $10 \%$ of these in the Southern Ocean would need to be instrumented to satisfy the sampling requirements proposed from our study.

\section{Appendix A}

[53] To derive the equation that describes the variance explained as a function of frequency we derived this relationship in one-dimension as follows. The variance in the time domain of time series, $h(k)$, of $N$ observations is given by:

$$
\begin{aligned}
\sigma_{\text {time }}^{2} & =\frac{1}{N} \sum_{k=0}^{N-1}|(h(k)-\overline{h(k)})|^{2} \\
& =\frac{1}{N} \sum_{k=0}^{N-1}\left\{h(k)^{2}-\overline{h(k)}^{2}\right\}
\end{aligned}
$$

Using the discrete Fourier Transform, the times-series to frequency-series, $H(n)$, is related as follows:

$$
\begin{gathered}
h(k)=\frac{1}{N} \sum_{n=0}^{N-1} H(n) e^{2 \pi i k n / N} \text { and } \\
H(n)=\sum_{k=0}^{N-1} h(k) e^{-2 \pi i k n / N}
\end{gathered}
$$

[54] By Parseval's Theorem the total power in the time domain to the total power in the frequency domain are related (as shown in any textbook on spectral analysis [e.g., Hzu, 1970]) by:

$$
\sum_{k=0}^{N-1} h(k)^{2}=\frac{1}{N} \sum_{n=0}^{N-1} H(n)^{2}
$$

Using the definition of the mean of the time series:

$$
H(0)=\sum_{k=0}^{N-1} h(k)=N \overline{h(k)}
$$

and substituting (A4) and (A3) into equation (A1), the relationship between variance in the time domain to variance in the frequency domain is:

$$
\begin{aligned}
\sigma_{\text {time }}^{2} & =\frac{1}{N^{2}} \sum_{n=0}^{N-1}\left\{H(n)^{2}-H(0)^{2}\right\} \\
& =\frac{1}{N^{2}} \sum_{n=1}^{N-1} H(n)^{2}=\sigma_{\text {freq }}^{2}
\end{aligned}
$$

We use equation (A5) to define the SNR resolved by frequencies below $f$ as:

$$
\operatorname{SNR}(f)=\frac{\sum_{n=1}^{f} H_{\text {signal }}(n)^{2}}{\sum_{n=1}^{f} H_{\text {noise }}(n)^{2}}
$$

[55] Acknowledgments. We are grateful to Tom W. Trull for his discussions and assistance in improving this work. This research received support from the Australian Commonwealth Cooperative Research Program.

\section{References}

ARGO Science Team (1998), On the design and implementation of Argo: An initial plan for a global; array of profiling floats, Int. CLIVAR Proj. Off. Rep. 32 pp., GODAE Int. Proj. Off., Melbourne, Victoria, Australia. Aumont, O., C. Le Quéré, and J. C.Orr (2004), NOCES project: Interannual HOWTO, Inst. Pierre Simon Laplace, Paris. (Available at http://www.ipsl.jussieu.fr/OCMIP/phase3/simulations/NOCES/HOWTONOCES.html.)

Ballabrera-Poy, J., R. G. Murtugudde, J. R. Christian, and A. J. Busalacchi (2003), Signal-to-noise ratios of observed monthly tropical ocean color, Geophys. Res. Lett., 30(12), 1645, doi:10.1029/2003GL016995. 
Chen, D., L. M. Rothestein, and A. J. Busalacchi (1994), A hybrid vertical mixing scheme and its application to tropical ocean models, J. Phys. Oceanogr., 24, 2156-2179.

Conkright, M. E., et al. (2002), World Ocean Database 2001, NOAA Atlas NESDIS 42, edited by S. Levitus, 167 pp., NOAA, Silver Spring, Md.

Copin-Montégut, C. (1988), A new formula for the effect of temperature on the partial pressure of $\mathrm{CO}_{2}$ in seawater, Mar. Chem., 25, 29-37.

Copin-Montégut, C. (1989), Corrigendum to Copin-Montégut 1988: A new formula for the effect of temperature on the partial pressure of $\mathrm{CO}_{2}$ in seawater, Mar. Chem., 27, 143-144.

Dickson, A. G., and C. Goyet (1994), Handbook of methods for the analysis of the various parameters of the carbon dioxide system in sea water, ORNL/CDIAC-74, U.S. Dep. of Energy, Washington, D. C.

Enting, I. G., M. L. Wigley, and M. Heimann (1994), Future emissions and concentrations of carbon dioxide: Key ocean/atmosphere/land analyses, CSIRO Div. of Atmos. Res. Tech. Pap. 31, 118 pp., Hobart, Tasmania, Australia.

Francey, R. J., et al. (2003), The CSIRO (Australia) measurement of greenhouse gases in the global atmosphere, in Baseline Atmospheric Program Australia 1999-2000, edited by N. W. Tindale, N. Derek, and P. J. Fraser, Bur. of Meteorol., Melbourne, Victoria, Australia.

Friedlingstein, P., J. L. Dufresne, P. Cox, and P. J. Rayner (2003), How positive is the feedback between climate change and the carbon cycle? Tellus, Ser. B., 672-700

Garçon, V., F. Thomas, C. S. Wong, and J.-F. Minster (1992), Gaining insight into the seasonal variability of $\mathrm{CO}_{2}$ at ocean station $\mathrm{P}$ using an upper ocean model, Deep Sea Res., Part A, 39, 921-938.

Gent, P. R., and J. C. McWilliams (1990), Isopycnal mixing in ocean circulation models, J. Phys. Oceanogr., 20, 150-155.

Gould, J., et al. (2004), Argo profiling floats bring new era of in situ ocean observations, Eos Trans. AGU, 85, 179,190-191.

Hzu, H. P. (1970), Fourier Analysis, Simon \& Schuster, New York.

Kalnay, E. (1996), The NCEP/NCAR 40-year reanalysis project, Bull. Am. Meteorol. Soc., 77, 437-470.

Keeling, R. F., and T. P. Whorf (2003), Atmospheric $\mathrm{CO}_{2}$ concentrationsMauna Loa Observatory, Hawaii, 1958-2002 (revised July 2003), http:// cdiac.esd.ornl.gov/ndps/ndp001.html, Carbon Dioxide Inf. and Anal. Cent., Oak Ridge, Tenn

Körtzinger, A., et al. (2000), The international at-sea intercomparison of $f \mathrm{CO}_{2}$ systems during the R/V Meteor cruise 36/1 in the North Atlantic Ocean, Mar. Chem., 72, 171-192.

Louanchi, F., J. M. J. Hoppema, D. C. E. Bakker, A. Poisson, M. H. C Stoll, H. J. W. de Baar, B. Schauer, D. P. Ruiz-Pino, and D. WolfGladrow (1999), Modelled and observed sea surface $f \mathrm{CO}_{2}$ in the Southern Ocean: A comparative study, Tellus, Ser. B, 51, 541-559.

Mahadevan, A., M. Lévy, and L. Mémery (2004), Mesoscale variability of sea surface $p \mathrm{CO}_{2}$ : What does it respond to?, Global Biogeochem. Cycles, 18, GB1017, doi:10.1029/2003GB002102.

Matear, R. J. (2004), Ocean carbon cycle in a changing climate: Climate change detection, in The Ocean Carbon Cycle and Climate, edited by M. Follows and T. Oguz, pp. 297-315, Elsevier, New York.

Matear, R. J., and A. C. Hirst (1999), Climate change feedback on the future oceanic $\mathrm{CO}_{2}$ uptake, Tellus, Ser. B, 51, 722-733.

McKinley, G. A., C. Rodenbeck, M. Gloor, S. Houweling, and M. Heimann (2004), Pacific dominance to global air-sea $\mathrm{CO}_{2}$ flux variability: A novel atmospheric inversion agrees with ocean models, Geophys. Res. Lett., 31, L22308, doi:10.1029/2004GL021069.

Mémery, L., M. Levy, S. Verant, and L. Merlivat (2002), The relevant time scales in estimating the air-sea $\mathrm{CO}_{2}$ exchange in a mid-latitude region, Deep Sea Res. Part II, 49, 2067-2092.

Metzl, N., B. Tilbrook, and A. Poisson (1999), The annual $f \mathrm{CO}_{2}$ cycle and the air-sea $\mathrm{CO}_{2}$ flux in the sub-Antarctic Ocean, Tellus, Ser, B, 5l, 849-861.

Nightingale, P. D., G. Malin, C. S. Law, A. J. Watson, P. S. Liss, M. I. Liddicoat, J. Boutin, and R. C. Upstill-Goddard (2000), In situ evaluation of air-sea gas exchange parameterizations using novel conservative and volatile tracers, Global Biogeochem. Cycles, 14, 373-388.

Pacanowski, R. C., and S. M. Griffies (1999), The MOM 3 Manual, Princeton Univ. Press, Princeton, N. J.

Prentice, I. C., et al. (2001), The carbon cycle and atmospheric $\mathrm{CO}_{2}$, in Contribution to Working Group I to the Third Assessment Report of the Intergovernmental Panel on Climate Change, edited by J. T. Houghton and D. Yihui, pp. 183-287, Cambridge Univ. Press, New York.

Rayner, P. J., I. G. Enting, R. J. Francey, and R. Lagenfelds (1999), Reconstructing the recent carbon cycle from atmospheric $\mathrm{CO}_{2}$, delta ${ }^{13} \mathrm{C}$ and $\mathrm{O}_{2} / \mathrm{N}_{2}$ observations, Tellus, Ser. B, 51, 213-232.

Redfield, A., B. Ketchum, and F. Richards (1963), The influence of organisms on the composition of the seawater, in The Sea, vol. 2, edited by M. Hill, pp. 26-77, Wiley-Intersci., Hoboken, N. J.
Reynolds, R. W., and T. M. Smith (1994), Improved global sea surface temperature analyses using optimal interpolation, J. Clim., 7, 929-948. Rödenbeck, C. S., S. Houweling, M. Gloor, and M. Heimann (2003), $\mathrm{CO}_{2}$ flux history 1982-2001 inferred from atmospheric data using a global inversion of atmospheric transport, Atmos. Chem. Phys., 3, $1919-1964$

Roy, T., P. J. Rayner, R. J. Matear, and R. Francey (2003), Southern Hemisphere ocean $\mathrm{CO}_{2}$ uptake: Reconciling atmospheric and oceanic estimates, Tellus, Ser. B, 55, 701-710.

Sabine, C. L., and R. M. Key (1998), Controls on $f\left(\mathrm{CO}_{2}\right)$ in the South Pacific, Mar. Chem., 60, 95-110.

Sabine, C. L., et al. (2004), The oceanic sink for anthropogenic $\mathrm{CO}_{2}$, Science, 305, 367-371.

Schiller, A., S. E. Wijffels, and G. A. Meyers (2004), Design requirements for an Argo Float Array in the Indian Ocean inferred from observing system simulation experiments, J. Atmos. Oceanic Technol., 21, 15981620.

Sweeney, C., T. Takahashi, and R. Wannikhof (2000), Spatial and temporal variability of surface water $p \mathrm{CO}_{2}$ and sampling strategies, report presented at Advisory Meeting for Sea-Air $\mathrm{CO}_{2}$ Flux Program, Natl. Oceanic and Atmos. Admin, Boulder, Colo.

Sweeney, C., T. Takahashi, A. Gnanadesikan, R. Wanninkhof, R. A. Feely, G. Friedrich, F. Chaves, N. Bates, J. Olafsson, and J. L. Sarmiento (2002), Spatial and temporal variability of surface water $p \mathrm{CO}_{2}$ and sampling strategies (appendix D), in A Large-Scale $\mathrm{CO}_{2}$ Observing Plan: In Situ Oceans and Atmosphere (LSCOP), pp. 155-175, NOAA Off. of Global Programs, Washington, D. C.

Takahashi, T., and C. Sweeney (2002), Errors in sea-air $\mathrm{CO}_{2}$ flux due to time-space ocean sampling strategies for sea-air $p \mathrm{CO}_{2}$ difference, in A Large-Scale $\mathrm{CO}_{2}$ Observing Plan: In Situ Oceans and Atmosphere (LSCOP), pp. 177-183, NOAA Off. of Global Programs, Washington, D. C

Takahashi, T., R. A. Feely, R. F. Weiss, R. H. Wanninkhof, D. W. Chipman, S. C. Sutherland, and T. T. Takahashi (1997), Global air-sea flux of $\mathrm{CO}_{2}$ : An estimate based on measurements of sea-air $p \mathrm{CO}_{2}$ difference, Proc. Natl. Acad. Sci. U. S. A., 94, 8292-8299.

Takahashi, T., et al. (2002), Global sea-air $\mathrm{CO}_{2}$ flux based on climatological surface ocean $p \mathrm{CO}_{2}$ and seasonal biological and temperature effects, Deep Sea Res., Part II, 49, 1601-1622.

Volk, T., and M. I. Hoffert (1985), Ocean carbon pumps: Analysis of relative strengths and efficiencies in ocean-driven atmospheric $\mathrm{CO}_{2}$ changes, in The Carbon Cycle and Atmospheric $\mathrm{CO}_{2}$ : Natural Variations Archean to Present, Geophys. Monogr. Ser., 32, edited by E. T. Sundquist and W. S. Broecker, pp. 99-110, AGU, Washington, D. C.

Walsh, J. (1978), A data set on Northern Hemisphere sea ice extent, in Glaciological Data, Rep. GD-2, part 1, pp. 49-51, World Data Cent. A for Glaciol. Snow and Ice, Boulder, Colo.

Wanninkhof, R. (1992), Relationship between wind speed and gas exchange over the ocean, J. Geophys. Res., 97, 7373-7382.

Watson, A. J., and J. C. Orr (2003), Carbon dioxide fluxes in the global ocean, in Ocean Biogeochemistry: The Role of the Ocean Carbon Cycle in Global Change, edited by M. J. R. Fasham, pp. 123-143, Springer, New York.

Weiss, R. F., and B. A. Price (1980), Nitrous oxide solubility in water and seawater, Mar: Chem., 8, 347-359.

Wetzel, P., A. Winguth, and E. Maier-Reimer (2005), Sea-to-air $\mathrm{CO}_{2}$ flux from 1948 to 2003: A model study, Global Biogeochem. Cycles, 19, GB2005, doi:10.1029/2004GB002339.

Yamanaka, Y., and E. Tajika (1996), The role of vertical fluxes of particulate organic material and calcite in the oceanic carbon cycle: Studies using an ocean biogeochemical general circulation model, Global Biogeochem. Cycles, 10, 361-382.

Zwally, H. J., C. J. C. Parkinson, W. Campbell, F. Carsey, and P. Gloerson (1983), Antarctic Sea Ice, 1973-1976: Satellite passive microwave observations, NASA Spec. Publ., SP-459.

A. Lenton, Laboratoire d'Océanographie et du Climat: Expérimentations et Approaches Numériques (LOCEAN/IPSL), Université Pierre et Marie Curie, 4 place Jussieu, F-75005 Paris, France. (andrew.lenton@lodyc. jussieu.fr)

R. J. Matear and B. Tilbrook, Antarctic Climate and Ecosystem Cooperative Research Centre (ACE CRC), University of Tasmania, Private Bag 80, Hobart, Tasmania 7001, Australia. (richard.matear@csiro.au; bronte.tilbrook@csiro.au) 